\title{
Eating behavior style predicts craving and anxiety experienced in food-related virtual environments by patients with eating disorders and healthy controls
}

Marta Ferrer-García ${ }^{1}$, Joana Pla-Sanjuanelo ${ }^{1}$, Antonios Dakanalis ${ }^{2}$, Ferran Vilalta-Abella ${ }^{1}$, Giuseppe Riva ${ }^{3}$, Fernando Fernandez-Aranda ${ }^{4}$, Isabel Sánchez ${ }^{4}$, Joan Ribas-Sabaté ${ }^{5}$, Alexis

Andreu-Gracia ${ }^{5}$, Neli Escandón-Nagel ${ }^{6}$, Osane Gomez-Tricio ${ }^{7}$, Virginia Tena ${ }^{8}$, José

Gutierrez-Maldonado ${ }^{1}$

${ }^{1}$ Department of Clinical Psychology and Psychobiology, University of Barcelona, Barcelona, Spain

${ }^{2}$ Department of Medicine and Surgery, University of Milano Bicocca, Milan, Italy

${ }^{3}$ Applied Technology for Neuro-Psychology Lab. Istituto Auxologico Italiano, Milan, Italy

${ }^{4}$ Department of Psychiatry, University Hospital of Bellvitge-IDIBELL, Barcelona, Spain

${ }^{5}$ Department of Psychiatry and Mental Health, Igualada General Hospital, Barcelona, Spain

${ }^{6}$ Catholic University of Temuco, Chile

${ }^{7}$ Department of Psychiatry, University Hospital Joan XXIII, Spain

${ }^{8}$ Centro ABB Tarragona, Spain

\section{Abstract}

Eating behavior style (emotional, restrictive, or external) has been proposed as an explanation for the differences in response to food-related cues between people who overeat and those who do not, and has been also considered a target for the treatment of eating disorders (EDs) characterized by lack of control over eating and weight-related (overweight/obesity) conditions. The aim of this study was to analyze the relationship between eating behavior style and psychophysiological responses (self-reported food craving and anxiety) to food-related

\footnotetext{
Correspondence to:

Marta Ferrer-Garcia

Department of Clinical Psychology and Psychobiology

University of Barcelona

Paseo Valle de Hebrón, 171

08035, Barcelona, Spain

Phone: 0034933125114

Fax: 0034934021362

E-mail: martaferrerg@ub.edu
} 
25 virtual reality (VR) environments in outpatients with bulimia nervosa (BN) and binge eating 26 disorder (BED) and to compare them with healthy participants. Fifty-eight outpatients and 135 27 healthy participants were exposed to palatable foods in four experimental everyday real-life 28 VR environments (kitchen, dining room, bedroom and café). During exposure, cue-elicited 29 food craving and anxiety were assessed. Participants also completed standardized instruments 30 for the study purposes. ED patients reported significantly higher levels of craving and anxiety 31 when exposed to the virtual food than healthy controls. Eating behavior styles showed strong 32 associations with cue-elicited food craving and anxiety. In the healthy group, external eating was the only predictor of cue-elicited craving and anxiety. In participants with BN and BED, external and emotional eating were the best predictors of cue-elicited craving and anxiety, respectively.

37 KEYWORDS: Food craving, anxiety, external eating, emotional eating, restraint eating, virtual 38 reality, cue-exposure therapy, bulimia nervosa, binge eating disorder 


\section{INTRODUCTION}

Overweight (Body mass index, BMI $\geq 25 \mathrm{~kg} / \mathrm{m} 2$ ) and obesity (BMI $\geq 30 \mathrm{~kg} / \mathrm{m} 2$ ) have grown alarmingly during last years in most world's countries. According to the World Health Organization (WHO), in 2014, $39 \%$ of adults aged 18 years and over (38\% of men and $40 \%$ of women) were overweight and $13 \%$ (11\% of men and $15 \%$ of women) were obese (WHO, 2015). This is more than half of the world's adult population and data are not more encouraging when analyzing pediatric samples. Beyond body image dissatisfaction and self-esteem concerns, these conditions are associated with chronic adverse health effects, disability, social stigmatization and a reduction in the overall quality of life and life expectancy (Calle, Teras, \& Thun, 2005; Capodaglio, Faintuch, \& Liuzzi, 2013; Malnick \& Knobler, 2006; Riva, Gaggioli, \& Dakanalis, 2013). Importantly, binge eating (wherein one consumes a large amount of food whilst experiencing a sense of loss of control over eating) required for diagnoses of bulimia nervosa (BN) and binge eating disorder (BED) (American Psychiatric Association [APA], 2013), is a consistent predictor of overweight status and strongly associated with greater obesity severity, and increased risk for obesity-related chronic illnesses (Sonneville et al., 2013; Tanofsky-Kraff et al., 2009).

Relevant explanations of human overweight and obesity include the growth of modern lifestyles with the availability of energy-dense food and the rise of sedentariness (Capodaglio et al., 2013; Maffeis, 2000). Despite the potency of this obesogenic environment, however, not all people become overweight (van Strien, Herman, \& Verheijden, 2009). Indeed, there are individual differences that may moderate and/or mediate responses to continuous exposure to high palatable food-related stimuli (Blundell et al., 2005). Eating styles (i.e., specific patterns of eating) have been proposed to explain response differences to obesogenic environments (Burton, Smit, \& Lightowler, 2007; van Strien, Herman, \& Verheijden, 2012). Three main eating styles, having their own aetiology (see below), are thought to be closely associated to overeating and weight gain -emotional, restrictive and external eating (Braet \& van Strien, 1997; Dakanalis et al., 2013, 2014; Van Strien, Herman, \& Verheijden, 2012).

Emotional eating or eating in response to internal emotional factors (i.e., fear, anxiety) is recognized as a risk factor for developing overweight (Van Strien, Herman, \& Verheijden, 2012) and has been extensively addressed by the psychosomatic theory (Bruch, 1964). According to this theory and related longitudinal research (Dakanalis et al., 2014) increased food intake in response to emotional distress may occur in some individuals who, as a result of learning experiences early in life where food was used as a way of coping with psychological 
distress, confuse internal emotional factors with hunger, due to poor interoceptive awareness. Likewise, individuals may paradoxically develop an overweight physique by consciously restricting food intake to lose or maintain a particular body weight (i.e., restrained eating) irrespective of whether they are emotional or external eaters (Van Strien, Frijters, Bergers, \& Defares, 1986). This eating pattern was addressed by Herman and Polivy's (1980) theory of restrained eating and based on their laboratory work, in which individuals who restrained their food intake overate when their self-control was deliberately undermined. Eating in response to external stimuli (i.e., external eating), involving a decreased sensitivity to internal signals of hunger and satiety, has been addressed by externality theory (Schachter, 1971), according to which overweight/obese people are externally controlled or stimulus-bound, i.e., more reactive to food-related external cues and less sensitive to internal hunger and satiety signals than normal-weight people. While both the psychosomatic and externality theories start from the premise that people with overeating behavior have a lower awareness of internal signals of hunger and satiety, the externality theory goes further by highlighting that overeaters have also a heightened responsiveness to external cues of food, such as the smell, sight, and taste of food. Consequently, intake in overweight people would be externally guided, which represents a major problem if we take into account the huge number of food-related stimuli that continually bombard us in the modern world. By reviewing the history of and research on "external cues" as an important factor in the control of human food intake, Herman and Polivy (2008) introduced a distinction between normative and sensory external cues. According these authors, normative cues (e.g., portion size) refer to indicators of appropriate intake and affect all eaters indiscriminately, whereas sensory cues that refer to the properties of the food that make it more or less appetizing (e.g., high palatability) have a more powerful effect on certain people (obese, dieting, or hungry individuals); for further details, including evidence that the sensory effect is grounded in physiology, see, Herman and Polivy (2008).

A heightened reactivity to environmental food-related cues such as the sight and smell of food has been proposed to increase food craving, i.e. an appetitive motivational state that promotes the ingestion of desired foods (Brockmeyer et al. 2015) even in a state of satiety, and consequently, food intake (Burton et al., 2007; Ferriday \& Brunstrom, 2011; Nederkoorn \& Jansen, 2002; Nederkoorn, Smulders, \& Jansen, 2000; van Strien et al., 2012). However, research reveals that not only the external eating style (Nederkoorn, Smulders, Havermans, \& Jansen, 2004; Nederkoon, Smulders, \& Jansen, 2000; van Strien \& Ouwens, 2003) but also the restraint (Cepeda-Benito, Fernandez, \& Moreno, 2003; Dakanalis et al., 2015; Hill, Weaver, \& 
Blundell, 1991; Nammi, Saisudha, Chinnala, \& Boini, 2004) and emotional eating (Dakanalis et al., 2014; Davis, Levitan, Smith, Tweed, \& Curtis, 2006; Deaver, Miltenberger, Smyth, Meidinger, \& Crosby, 2003; van Strien et al., 2009; Wardle et al., 1992) styles are related to higher levels of food craving and binge eating. Given also the positive associations between food cravings and excessive overeating (Brockmeyer et al., 2015; Hetherington \& Mcdiarmid, 1995), BMI (Burton et al., 2007) binge eating, BED and BN (Chao, Grilo, \& Sinha, 2016; Greeno, Wing, \& Schiffman, 2000; Joyner, Gearhardt, \& White, 2015; Waters, Hill, \& Waller, 2001), an increasing body of studies have focused on the relation between eating styles, food craving (a frequently cited antecedent of binge eating; Chao, et al., 2016; Schulte, Grilo \& Gearhardt, 2016), and lack of control over eating. The results of these studies have been inconsistent to date, emphasizing the complexity of these relations. In their research, Burton and colleagues (2007) found external eating to be the principal predictor of food craving in both males and females; however, restrained eating was negatively associated with craving in females, while emotional eating was not significantly associated with food craving. In other research, a positive and significant correlation between binge behavior and both external eating and emotional eating has been found (Mason \& Lewis, 2014). Such responsiveness to food cues is not specific to overweight people according to van Strien and colleagues (2009), but is a general characteristic of humans. Indeed, according to Rodin (1981), external eating may be an evolutionary adaptive response that is related to the concept of a thrifty genotype (Neel, 1962).

Heightened reactivity to food-related cues has also been proposed to elicit anxiety in individuals with binge behaviors. Martínez-Mallén et al. (2007) stated that exposure to foodrelated cues elicits not only food craving but also anticipatory anxiety, and that it is this anxiety that leads to binge behaviors. On the bases of this model, the association between food-related cues and anxiety is established during the initial stages of the bulimic condition. After binges, individuals experience negative emotions, such as shame, guilty, and discomfort. With time, people who binge associate those foods usually eaten during binges, as well as other specific and contextual cues (environmental and temporal), with high levels of anticipatory anxiety. This anxiety can lead to what the authors name "bulimic hunger" (Martínez-Mallén et al.,2007). Despite the fact that this model has not been studied enough, data suggest that anxiety elicited by food exposure better discriminates between clinical and non-clinical samples than craving (Pla-Sanjuanelo et al., submitted). Whereas a certain level of craving is expected to be found in non-clinical samples when they are exposed to palatable food (Ferrer-Garcia, 
Gutiérrez-Maldonado, Treasure, \& Vilalta-Abella, 2015; Nederkoorn, Smulders, Havermans, Jansen, 2004), anxiety levels are expected to be low in these samples, given that food is not a stressful stimulus for healthy people.

Taking into account these studies, it may be worth considering patients' eating styles in the treatment of eating disorders (EDs) characterized by binge eating (i.e., BN and BED) and weight-related (overweight/obesity) conditions. Indeed, theoretical models based on the study of external food-cue reactivity (Schachter, 1971) provide a rationale for exposure with response prevention of bingeing, also known as cue-exposure therapy (CET) (Gutiérrez-Maldonado, Ferrer-Garcia, \& Riva, 2013; Koskina, Campbell, \& Schmidt, 2013). According to the conditioning model of binge eating (Jansen, 1998) highlighting the learning processes that underlie physiological and craving responses to food cues, repeated exposure to specific stimuli (food-related cues that are systematically associated with binge eating, such as the presence of high caloric food) provokes a psychophysiological response that is subjectively experienced as food craving, and triggers binge eating. When binging occurs, its association with food cues is reinforced, thereby increasing the probability of further binge episodes. CET aims to extinguish the craving response by breaking the link between the conditioned and the unconditioned stimuli through the repeated exposure to food-related cues (conditioned stimuli) while binging (unconditioned stimulus) is prevented (Koskina et al. 2013). As abovementioned, MartínezMallén et al. (2007) proposed a variation of this model and stated that exposure to food-related cues also elicits anticipatory anxiety, being this anxiety which triggers binge behavior. Linked with the specification of Herman and Polivy (2008), the conditioned stimuli would include both normative and sensory food cues, with the latter particularly affecting patients with binge eating behavior.

Although several studies, reviewed elsewhere (Gutiérrez-Maldonado et al., 2013; Koskina et al., 2013) have provided evidence of the efficacy of CET for the treatment of EDs characterized by binge-eating, the use of CET has not become widespread, probably because CET did not add significant benefits to cognitive behavioral therapy (Bulik, Sullivan, Carter, McIntosh, \& Joyce, 1998) (CBT), mainly due its logistic complexity (Bulik et al., 1998; Martínez-Mallén et al., 2007). As an alternative to in vivo therapy, virtual reality (VR) technology has been proposed as a means of administering CET (Gutiérrez-Maldonado, Wiederhold, \& Riva, 2016). VR, which has demonstrated its efficacy as a tool for assessing and treating EDs (Ferrer-Garcia, Gutiérrez-Maldonado, \& Riva, 2013), overcomes the characteristic logistical drawbacks of in vivo exposure, and the process allows therapists to 
maintain high levels of control over the exposure situation, as well as the ability to expose patients to contextual and specific cues.

Previous research provides evidence of the ability of VR environments to generate emotional and behavioral responses in ED patients similar to those expected in real-life situations (Aimé, Cotton, \& Bouchard, 2009; Ferrer-Garcia, Gutiérrez-Maldonado, CaqueoUrízar, \& Moreno, 2009; Gorini, Griez, Petrova, \& Riva, 2010; Gutiérrez-Maldonado, FerrerGarcía, Caqueo-Urízar, \& Moreno, 2010). There is even evidence that VR-based food-cue exposure can induce craving responses in both healthy and clinical (i.e., ED patients) groups (Agliaro-López, Ferrer-García, Pla-Sanjuanelo, \& Gutiérrez-Maldonado, 2014; Ferrer-Garcia, Gutiérrez-Maldonado, \& Pla, 2013; Ferrer-Garcia, Gutiérrez-Maldonado, Treasure, \& VilaltaAbella, 2015), though the results have not always been consistent (Ledoux, Nguyen, BakosBlock, \& Bordnick, 2013). Studies have shown that healthy participants reported higher levels of craving when exposed to high-calorie foods than when exposed to low-calorie foods (FerrerGarcia, Gutiérrez-Maldonado, Treasure et al.,2015) and that food craving experienced in VR environments was associated with trait and state food craving assessed outside VR environments (Agliaro-López et al., 2014; Ferrer-Garcia et al., 2013). More interestingly, reported food craving in these studies was similar to that found in studies conducted with real food (Tetley, Bunstrom, \& Griffiths, 2009). However, not all food cues produced the same levels of craving. Consistent with Herman and Polivy's (2008) distinction between normative and sensory external cues, higher levels of craving were associated with exposure to highly palatable food in the aforementioned studies. Likewise, previous studies found that ED patients and individuals concerned with their weight and shape reported higher levels of anxiety when exposed to high-calorie foods than when exposed to low-calorie foods in VR environments (Aimé et al, 2009; Ferrer-Garcia et al., 2009; Ferrer-Garcia et al., 2015). Now, it is necessary to go a step further and deeper into the relationship between the reactivity to virtual food in VR environments and the eating behavior style reported by healthy controls and patients characterized by binge eating (i.e., with BN, BED).

The main objectives of this study are to: (a) analyze the relationship between eating style and psychophysiological responses to food-related VR environments (specifically, food craving and anxiety), and (b) evaluate whether this relationship was different in patients with $\mathrm{ED}$ (BN and BED) to that in healthy participants. A previous preliminary study by our group showed that an external eating style was the best predictor of food craving experienced in VR environments, after controlling for the percentage of variance explained by the presence of an 
ED diagnosis (variable entered in the first step of a hierarchical multiple regression analyses) (Ferrer-Garcia, Gutiérrez-Maldonado, Pla-Sanjuanelo et al., 2015). In the present study, this research was replicated enlarging the sample and assessing participants with and without EDs separately in order to explore differences between the clinical and healthy/control groups. We also considered anxiety as a dependent variable because, along with food craving, it is known to be related to binge eating (Leehr, Krohmer, Schag, Dresler, Zipfel, \& Giel, 2015; Satta et al., 2016). In accordance with abovementioned studies, a positive relationship was expected between the eating style and food craving experienced in VR environments. Given that individuals with an external eating style show a heightened responsiveness to external foodcues (Schachter, 1971), it was expected that the association between external eating style and food craving would be stronger than the association with emotional and restraint eating styles (H1). The relationship between eating style and food craving was expected to be stronger in patients with $\mathrm{BN}$ and BED than in healthy participants (H2). Likewise, it was expected that eating styles, especially external eating, would be good predictors of food craving experienced in the VR environments in both groups (H3). The association between eating behavior style and the presence of cue-elicited anxiety in the VR environments was also explored. Despite a lack of previous research addressing this issue, the already mentioned model proposed by Martínez-Mallén et al. (2007) was adopted, indicating that anxiety elicited by food cues leads to binge eating behavior in ED patients. Given that, a positive relationship was expected between the eating style, especially the external eating, and the anxiety experienced in the VR environments (H4). Again, this association was expected to be stronger in patients with BN and BED than in healthy participants (H5). It was also expected that the eating styles, especially the external eating, would be good predictors of anxiety experienced in the VR environments in both groups (H6).

\section{METHODS}

\section{Participants}

The clinical (ED) group included 58 outpatients (13 men and 45 women), of whom 33 met DSM-5 (APA, 2013) criteria for BN and 25 criteria for BED. Mean age was 33.94 years ( $\mathrm{SD}=10.84$, range 18 to 63 ). Mean (measured) body mass index (BMI) was 27.26 ( $\mathrm{SD}=5.60$, range from 17.95 to 40.61). All participants were recruited from collaborating hospitals and health centers including the Hospital de Bellvitge (Barcelona, Spain), Adult Mental Health 
Center of the Consorcio Sanitario de la Anoia (Igualada, Spain), Hospital Universitari Joan XXIII (Tarragona, Spain), and the Instituto Auxologico Italiano (Milan, Italy). Inclusion criteria were a diagnosis of BN or BED according to DSM-5, and age over 18. Diagnostic interviews were conducted in each one of the participating hospitals. Patients with suicidal ideation or any comorbid psychiatric disorder were excluded from the study.

The control group consisted of 135 healthy participants (13 men and 122 women) recruited from among college students from the faculty of psychology at the University of Barcelona. Mean age was 23.39 years ( $\mathrm{SD}=4.35$, range 19 to 56) and mean (measured) BMI 21.71 (SD $=3.01$, range 16.58 to 34.77). Participants with (past or current) diagnosis of any ED or psychiatric disorder were excluded.

All participants gave their written informed consent prior to entry in the study. The protocol was approved by the research ethics committees of the collaborating institutions.

\section{Instruments}

\section{Food CET software and hardware}

VR-based software for CET in binge eating behaviors was recently developed and validated by our research group (Pla-Sanjuanelo et al., submitted). It includes a library of 30 virtual sweet and savory foods, frequently consumed by patients with ED during binge eating episodes (e.g. cake, pizza, chips, hot dog, cookies, ice-cream, chocolates, rolls/buns, donuts, brownies), as well as 4 everyday real-life VR environments where they usually binge (kitchen, dining room, bedroom, and cafeteria) (Pla-Sanjuanelo et al., 2015). Non-immersive virtual environments were displayed on a 15.6-inch stereoscopic monitor (Pla-Sanjuanelo et al., submitted). Earphones and polarized glasses were also used.

\section{Measures}

The eating behavior style was assessed using the Spanish (Cebolla, Barrada, van Strien, Oliver, \& Baños, 2014) and Italian (Dakanalis et al., 2013) versions of the Dutch Eating Behavior Questionnaire (DEBQ; Van Strien, Frijter, Bergers, \& Defares, 1986). This questionnaire contains 33 items grouped in three subscales: emotional eating (13 items), external eating (10 items), and restraint eating (10 items). All items are rated on 5-point scales with response categories ranging from 1 (never) to 5 (very often). The references provided contain information regarding the psychometric properties of the original Spanish and Italian 
versions of the instrument. In the current study, the alpha coefficients were $.93, .85$ and .93 for emotional eating, external eating, and restraint eating respectively.

In line with previous research (Pla-Sanjuanelo et al., 2015) revealing a significant association between food craving and the frequency/severity of binge eating behavior assessed through the Bulimia subscale of the EDI-3 (EDI-B), this subscale was also administrated. The Spanish (Elosua, López-Jáuregui, \& Sánchez-Sánchez, 2010; Elosua \& López-Jáuregui, 2012) and Italian (Garner, 2008) adaptations of the EDI-3 (Garner, 2004) were used in the current study. The EDI-B measures the individual's tendency to engage in episodes of uncontrollable overeating (binge eating) (Garner, 2004, 2008; Dakanalis et al., 2014) on a 5-point scale from 0 (never) to 4 (always). The subscale, which has demonstrated good psychometric properties (Elosua et al. 2010; Elosua \& López-Jáuregui, 2012; Garner, 2004, 2008), showed good reliability $(\alpha=.96)$ in this study.

Food craving and anxiety experienced in the VR environments were measured using a $100 \mathrm{~mm}$ visual analog scale (VAS) (Parker et al., 2004), anchored with the statements "Set on the bar, from 0 (not at all) to 100 (extremely), the level of food craving you experience at this time" and "Set on the bar, from 0 (not at all) to 100 (extremely), the level of anxiety you experience at this time". The VAS appeared on a computer screen, and participants were asked to click a point on the bar that best represented their level of craving or anxiety at that moment. Food craving and anxiety experienced in VR environments was associated with trait and state food craving and anxiety assessed outside VR environments (Pla-Sanjuanelo et al., submitted).

\section{Design and procedure}

This study followed a cross-sectional design in a single session, where the eating behavior style of the participants (assessed with the DEBQ) was considered the independent variable (predictor), whereas reported food craving and anxiety (assessed with VASs) during exposure to the virtual environments were considered dependent variables. Participants were informed of the nature of the study by the experimenter responsible for its administration. During the session, an experienced clinician accompanied the participant to offer help if needed.

After completing the DEBQ and EDI-B and reporting information regarding the length of time since the last meal (in minutes), study participants were exposed to the VR-based software developed for CET in binge eating (Pla-Sanjuanelo et al., submitted). First, they were exposed to a list of 30 bi-dimensional (2D) images of different virtual foods and asked to 
indicate the level of craving elicited by each food on a VAS ranged from 0 (not at all) to 100 (extreme), placed under each image. After this, they were exposed to a list of four 2D images of everyday real-life VR environments and again asked to rate the level of craving elicited on a VAS (from 0 to 100), placed under each image. With this information, the software creates an exposure hierarchy combining the four VR environments with the ten foods that elicited the highest levels of food craving. Thus, there were a total of 40 three-dimensional (3D) virtual situations (10 foods $\mathrm{x} 4 \mathrm{VR}$ environments) that progressed from the lowest to highest (registered) participants' scores: in the first steps of the hierarchy, participants were exposed to the foods that elicited the lowest levels of craving in each of the four VR environments, and during the final steps of the hierarchy they were exposed to the foods that provoked the highest levels of craving in the environment that provoked the highest levels of craving.

Once in the virtual situation (in all steps of the hierarchy), participants were asked to move around the scenario (using the laptop's mouse), to find the virtual table where the food was placed, and to sit down. Then, they were exposed to the food for 20 seconds. During this time, they were able to handle the virtual food using the laptop's mouse. Next, participants were asked to indicate the level of food craving and anxiety on a VAS from 0 to 100 (see also measures), displayed on the laptop's screen. Then, the participants were exposed to the following virtual situation, according to the pre-stablished hierarchy, and so on until being exposed to the 40 virtual environments. Anxiety and food-craving was assessed once in each VR situation. To increase the participant's immersion in the virtual environments, these environments were presented using stereoscopic laptops, and exposure was conducted individually in a quiet, darkened room. The evaluator/clinician also ensured that the participant's attention remained on the exposure task and, whenever necessary, reminded $\mathrm{him} / \mathrm{her}$ to focus on the laptop screen. The total duration of the session was approximately 40 minutes.

\section{Statistics}

Differences in eating styles between groups were assessed by parametric (Independentsamples t-test) and non-parametric (Mann-Whitney Test) analyses, with most of the variables not fitting normality assumptions ( $p<.05$ by the Kolmogorov-Smirnov test). Spearman's rank order correlation was performed to assess the association between mean food craving and anxiety experienced in virtual environments with scores obtained in the external, emotional, 
332

333

334

335

336

337

338

339

340

341

342

343

344

345

346

347

348

349

350

351

352

353

354

and restraint eating subscales of the DEBQ and EDI-B, as well as demographic and other assessed variables (age, BMI and time elapsed since the last meal). Correlations were conducted separately in patients with ED and controls to explore differences between the groups. Multiple regression analyses were also conducted separately in both groups. After controlling for (exploratory purposes) the effect of potential interaction variables, i.e., time elapsed since the last meal and BMI (see results for details), external, emotional, and restrictive eating subscales (of the DEBQ) were introduced as independent variables, and food craving and anxiety were used as dependent variables. The analyses were performed to assess whether participant's eating style was a good predictor of craving and anxiety experienced during foodrelated VR environments. To facilitate interpretation and reduce collinearity, all variables were standardized (calculation of z-score) before conducting the correlation and regression analyses (Brendgen, Girard, Vitaro, Dionne, \& Boivin, 2015; Cohen, Cohen, West, \& Aiken, 2003). Standardization was conducted before joining the Spanish and Italian patients. All analyses were conducted in SPSS v.23.

\section{RESULTS}

As shown in Table 1, patients with BN and BED, as compared with healthy controls, experienced higher levels of food craving and anxiety during exposure to the VR environments. Patients also reported higher levels of external, emotional, and restrictive eating, as well as frequency/severity of binge eating behavior (assessed by the EDI-B). Large effect sizes were found in all comparisons.

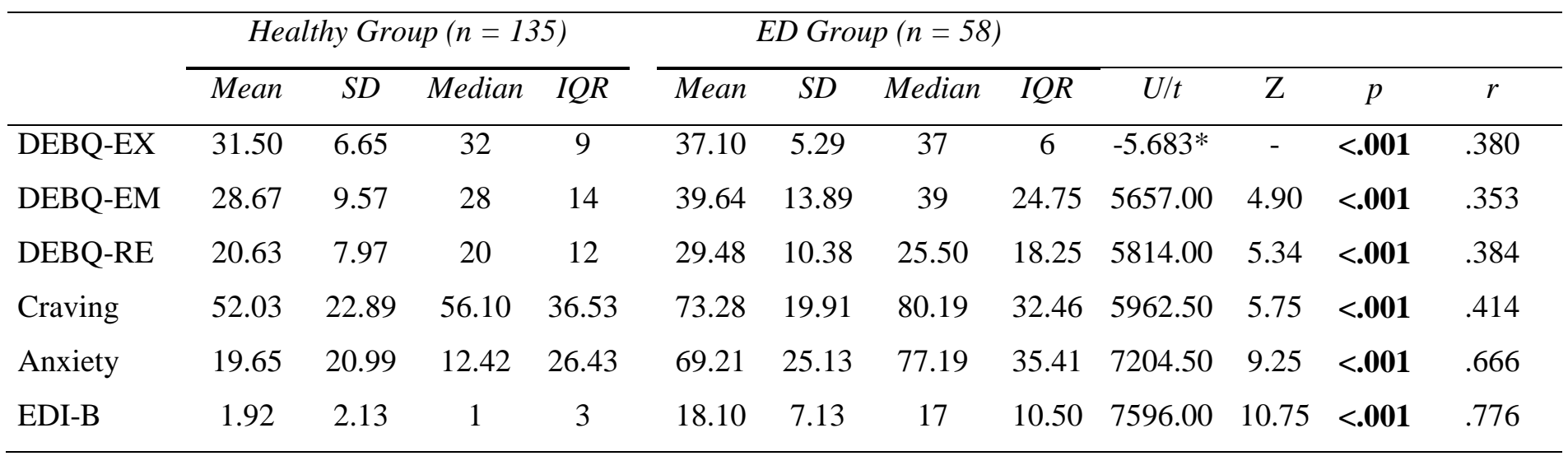

355 Note: DEBQ-EX (Dutch Eating Behavior Questionnaire-External Eating), DEBQ-EM (Dutch Eating Behavior

356 Questionnaire-Emotional Eating), DEBQ-RE (Dutch Eating Behavior Questionnaire-Restraint Eating), EDI-B 
(Bulimia scale of the Eating Disorders Inventory-3), SD (Standard Deviation), IQR (InterQuartile Rank)

* $T$-test was conducted to assess group differences in the DEBQ-EX scale. For the rest of variables, MannWhitney $U$ was used.

The results of the correlational analyses, shown in Table 2, indicate that there were positive significant associations between food craving and external eating and time elapsed since the last meal, and negative significant association between food craving and BMI, in the healthy group, whereas in the ED group, there were positive significant associations between food craving and external eating, emotional eating and time elapsed since the last meal. In the healthy group significantly positive associations between anxiety experienced in the VR environments, time elapsed since the last meal and all the DEBQ subscales were also evidenced. In the clinical (ED) group anxiety reported in the VR environments were also positively and significantly associated with the time elapsed since the last meal, emotional and external eating.

Table 2. Non-parametric correlations (Spearman Rho) in the healthy and ED group

\begin{tabular}{lcccccccc}
\hline & \multicolumn{3}{c}{ Healthy Group $(n=135)$} & \multicolumn{3}{c}{ ED Group $(n=58)$} \\
\hline & \multicolumn{2}{c}{ Food craving } & \multicolumn{2}{c}{ Anxiety } & \multicolumn{2}{c}{ Food craving } & \multicolumn{2}{c}{ Anxiety } \\
\cline { 2 - 10 } Age & $r$ & $p$ & $r$ & $p$ & $r$ & $p$ & $r$ & $p$ \\
BMI & .157 & .071 & .124 & .155 & -.189 & .156 & -.101 & .450 \\
Time & -.265 & $\mathbf{. 0 0 2}$ & .002 & .979 & -.174 & .191 & -.110 & .410 \\
DEBQ-EM & .306 & $<.001$ & .197 & $\mathbf{. 0 2 2}$ & .353 & $\mathbf{. 0 0 7}$ & .267 & $\mathbf{. 0 4 3}$ \\
DEBQ-EX & .088 & .308 & .251 & $\mathbf{. 0 0 3}$ & .351 & $\mathbf{. 0 0 7}$ & .469 & $<.001$ \\
DEBQ-RES & .380 & $<.001$ & .319 & $\mathbf{< . 0 0 1}$ & .455 & $<.001$ & .355 & $\mathbf{. 0 0 6}$ \\
& .068 & .437 & .213 & $\mathbf{. 0 1 3}$ & .221 & .096 & .145 & .276 \\
\hline
\end{tabular}

373

Note: DEBQ-EX (Dutch Eating Behavior Questionnaire-External Eating), DEBQ-EM (Dutch Eating Behavior Questionnaire-Emotional Eating), DEBQ-RE (Dutch Eating Behavior Questionnaire-Restraint Eating), BMI (Body Mass Index), ED (Eating Disorders).

Due to the small size of the sample (specially, the ED group, $n=58$ ), it was not possible to conduct hierarchical multiple regressions (according to Stevens, 1996, a minimum of 15 subjects per predictor is required). Instead, several multiple regression analyses were conducted introducing the three DEBQ subscales (emotional, external, and restrictive eating styles) as independent variables for predicting food craving and anxiety. Since previous research (FerrerGarcia, Gutiérrez-Maldonado, Pla-Sanjuanelo et al., 2015) reported associations between BMI 
383

384

385

386

387

388

389

390

391

392

393

394

395

396

397

398

399

400

and time elapsed since the last meal with anxiety, food craving, and style of eating behavior, these variables were controlled for (see appendices 1 and 2) before conducting the main multiple regression analyses. Overall, the aim was to detect potential variables that could modify the effect of eating behavior style on the dependent variable. Six multiple regression analyses were conducted in the ED and healthy groups to assess (for exploratory purposes) the potential modifying effect of BMI and time elapsed since the last meal. Each multiple regression included three predictor variables: one of the subscales of the DEBQ (emotional, external, or restrictive eating), one of the potential interaction variables (BMI or time elapsed since the last meal), and the interaction between both variables (for example, emotional eating $\times \mathrm{BMI})$. As shown in appendices 1 and 2 reporting the results of these multiple regression analyses, only the interaction between emotional eating and time elapsed since the last meal showed a significant effect over food craving in the ED group (Beta $=-.396, t=-2.694, p$ $=.009$ ). Once removed the variance effect of this interaction, the effect of emotional eating over craving increased slightly. These data should be kept in mind when considering the results of the following analyses.

Table 3. Results of the multiple regression analyses for food craving in the control and ED groups

\begin{tabular}{|c|c|c|c|c|c|c|c|c|c|}
\hline Mode & Predictors & Beta & $t$ & $p$ & $\overline{R^{2}}$ & $R_{\text {adj. }}^{2}$ & $F$ & $p$ & $d$ \\
\hline \multirow[t]{4}{*}{1} & Control Group & & & & .161 & .141 & 8.361 & $<.001$ & 2.104 \\
\hline & DEBQ-EM & -.124 & -1.314 & .191 & & & & & \\
\hline & DEBQ-EX & .435 & 4.914 & $<.001$ & & & & & \\
\hline & DEBQ-RE & .029 & .332 & .740 & & & & & \\
\hline \multirow[t]{4}{*}{1} & ED Group & & & & .265 & .224 & 6.488 & .001 & 2.192 \\
\hline & DEBQ-EM & .170 & 1.365 & .178 & & & & & \\
\hline & DEBQ-EX & .389 & 3.189 & .002 & & & & & \\
\hline & DEBQ-RE & .178 & 1.499 & .140 & & & & & \\
\hline
\end{tabular}

401

Note: DEBQ-EX (Dutch Eating Behavior Questionnaire-External Eating), DEBQ-EM (Dutch Eating Behavior

402

Questionnaire-Emotional Eating), DEBQ-RE (Dutch Eating Behavior Questionnaire-Restraint Eating)

403

$\mathrm{d}=$ Durbin-Watson statistic. Emotional, external, and restrictive eating styles were introduced as predictors.

404

Food craving in the VR environments was the dependent variable.

405

406

Table 4. Results of the multiple regression analyses for anxiety in the control and ED groups

\begin{tabular}{lrllcccccc}
\hline Model & Predictors & Beta & $t$ & $p$ & $R^{2}$ & $R_{\text {adj. }}^{2}$ & $F$ & $p$ & $d$ \\
\hline 1 & Control Group & & & & .137 & .117 & 6.937 & $<.001$ & 2.086
\end{tabular}




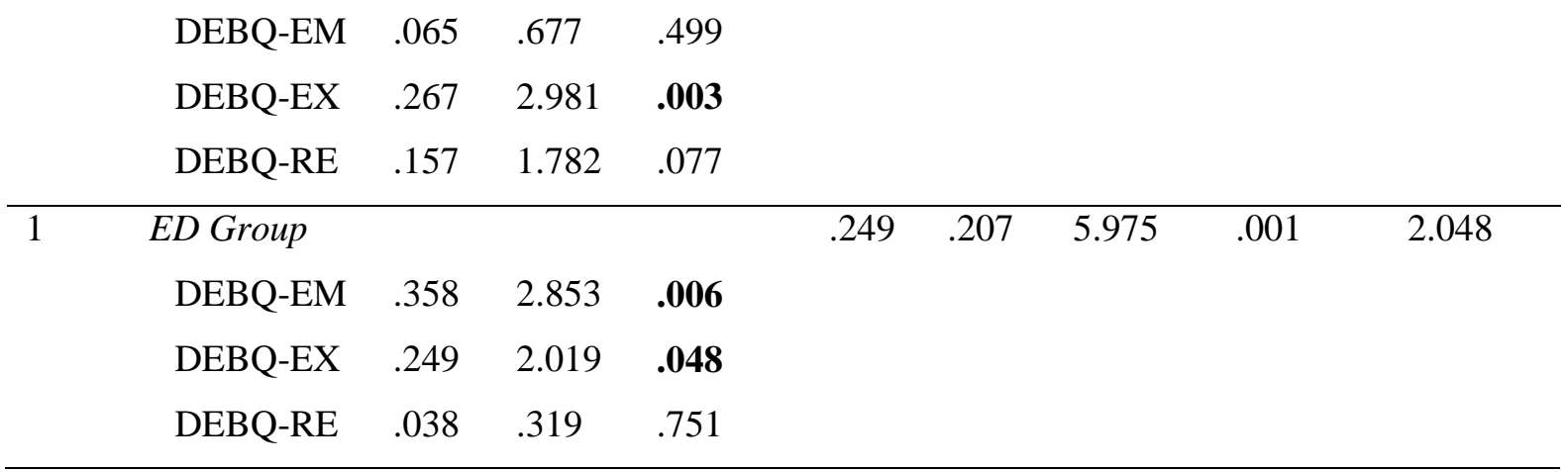

407

408

409

410

411

412

413

414

415

416

417

418

419

420

421

422

423

424

425

426

427

428

429

430

431

432

433

Note: DEBQ-EX (Dutch Eating Behavior Questionnaire-External Eating), DEBQ-EM (Dutch Eating Behavior Questionnaire-Emotional Eating), DEBQ-RE (Dutch Eating Behavior Questionnaire-Restraint Eating) $\mathrm{d}=$ Durbin-Watson statistic. Emotional, external, and restrictive eating styles were introduced as predictors. Anxiety in the VR environments was the dependent variable.

Multiple regression analyses were conducted separately in the healthy/control and clinical (ED) groups to clarify the relationship between eating behavior style and cue-elicited craving (Table 3) and anxiety (Table 4) in the VR environments. The eating style of participants accounted for $16 \%$ and $26.5 \%$ of the variation in food craving in the control and ED groups, respectively (Table 3). Interestingly, in both control and ED groups external eating was the only predictor that made a significant unique contribution to the model. The eating style of participants also accounted for comparable figures of $14 \%$ and $25 \%$ of the variation in anxiety in the control and ED groups, respectively (Table 4). In the control group, external eating was the only predictor that made a significant unique contribution to the model. In the ED group, both emotional and external eating made statistically significant individual contributions to the model, though emotional eating made a greater contribution.

\section{DISCUSSION}

The main objective of this study was to analyze the relationship between eating behavior styles, and self-reported food craving and anxiety to food-related virtual environments in BN and BED patients and healthy participants. Consistent with the cue-reactivity theory (Schachter, 1971), a positive relationship was found between the external eating style and food craving experienced in VR environments in the healthy/control and clinical (ED) groups. These results support previous research that also found higher levels of food craving in individuals (both healthy and with ED) with heightened reactivity to food cues (Brockmeyer et al., 2015; Ferrer-Garcia, Gutiérrez-Maldonado, Pla-Sanjuanelo et al., 2015). In their research, van Strien et al. (2009) stated that responsiveness to food cues may be a general characteristic of humans 
linked to Neel's thrifty genotype hypothesis. According to Neel (1962), there is a genetic predisposition to fatten rapidly during times of feast to better survive during times of famine, which is a characteristic inherited from the Paleolithic era. Emotional eating, a frequently cited antecedent of binge eating (Dakanalis et al., 2014; Van Strien \& Ouwens, 2007), was also positively associated with food craving in the ED group. However, when emotional eating was considered in conjunction with the other eating styles as predictors of craving, only external eating made a significant unique contribution to the model, as discussed below.

The results provide support to our first and second hypotheses. Specifically, in addition to the positive association between the external eating style and food craving experienced in the VR environments, this association was stronger in participants with BN and BED that in healthy controls. Furthermore, in agreement with our third hypothesis, participants' eating behavior style accounted for a considerable percentage of the craving experienced in the virtual environments, especially in the ED group, with external eating being the only predictor that made a significant contribution to explaining cue-elicited craving in both the control and ED groups. Burton et al. (2007) reported external eating to be the main predictor of craving in a healthy sample comprising men and women. Our results are also consistent with a previous study showing that, in a mixed sample of participants with and without EDs, external eating was the best predictor of food craving in VR environments (Ferrer-Garcia, GutiérrezMaldonado, Pla-Sanjuanelo et al., 2015). By also taking into account the results obtained in this study, we can draw two main conclusions. First, eating style seems to play a more decisive role when explaining food craving in patients with $\mathrm{BN}$ and BED than in participants without EDs. Second, when exposed to highly palatable food, external eating is probably the best predictor of craving. Consistent with Herman and Polivy's (2008) distinction between normative and sensory external cues, people who overeat in response to external cues (external eating) are especially sensitive to sensory food cues (i.e., highly appetizing and palatable). In the present study, participants were exposed to three-dimensional representations of foods that they had previously rated as producing the highest levels of desire to eat (e.g., highly palatable food). Thus, the external eating style acquires a more prominent role in such conditions.

Anxiety experienced during exposure to virtual food was also assessed in this study. A positive relationship was found between the external eating style and anxiety experienced in the VR environments, consistent with our fourth hypothesis. However, in contrast to our fifth hypothesis, this relation was similar in both the ED and control groups. Moreover, anxiety was significantly correlated with all eating styles assessed in the control group, but only with 
emotional and external eating in the ED group. Although the relationship between emotional eating and anxiety has been studied previously (Goossens, Braet, Van Vlierberghe, \& Mels, 2009; Mensorio et al., 2017), no attention has been deserved on the relationship between external eating and food-cue elicited anxiety, so far. Our results are, therefore, exploratory. The association between higher levels of emotional and external eating and higher levels of reported anxiety during exposure to food could, for example, be explained by anticipatory anxiety. According to the model proposed by Martínez-Mallén et al. (2007), exposure to highly palatable food may lead to anticipation of the risk of overeating and increase anxiety experienced by participants, but research lending credence to this suggestion is required. Concerning our sixth hypothesis, results revealed that external eating style predicted anxiety experienced during exposure to virtual food cues. However, while external eating was the only predictor of anxiety in the healthy/control group, the best predictor of anxiety in the ED group was emotional eating, though external eating also had a significant contribution. Again, the association between emotional discomfort and overeating behaviors in high emotional eaters probably explains anxiety responses for those with BN or BED when exposed to palatable or binge-related food cues, but further research in this area is required.

In summary, the results of this study extend the available evidence supporting the relationship between eating style and psychophysiological responses (craving and anxiety) to food-cue exposure. In controls without pathological eating behaviors, external eating was the only predictor of reported cue-elicited craving and anxiety. In participants with BN and BED, external eating was also the only predictor of cue-elicited craving, while emotional and external eating were predictors of cue-elicited anxiety, though emotional eating made a greater contribution. Finally, the study provides evidence of the ability of virtual food in virtual environments to generate these responses and detect differences between ED and non-ED groups.

Some limitations of this study should be mentioned. First, the ED sample was small, so the role of potential interaction between eating styles and other variables could not be considered in the regression analyses. To mitigate this limitation, several multiple regression analyses were conducted in both groups to control for the potential modifying effect of BMI and time elapsed since the last meal on eating style when predicting food craving and anxiety. Although useful, this solution is not perfect, as raises the probability of type II error. Consequently, this is something that should be kept in mind when construing the results. Second, control group is 10 years younger than ED group (mean age of 23.4 and 33.9, 
respectively). Despite the fact that age was not significantly associated with reported food craving and anxiety in this study, previous research has suggested that the levels of experienced food craving decrease in elderly (Pelchat, 1997). Third, the percentage of male participants was very low compared with the percentage of female participants. Consequently, sex differences could not be considered, which is important because previous studies have shown higher levels of food craving in women than in men (Cepeda-Benito, Fernandez, \& Moreno, 2003; Weingarten \& Elston, 1991). However, Burton et al. (2007) found that this difference was specific for sweet foods, but not for other kinds of food. Likewise, sex differences have also been observed in eating behavior patterns, with women usually reporting higher levels of emotional and restraint eating styles while men report higher levels of external eating (Burton et al., 2007; Delahanty, Meigs, Hayden, Williamson, \& Nathan 2002; Neumark-Sztainer, Sherwood, French, \& Jeffery, 1999; Waller \& Matoba, 1999). Future research should address these differences. Finally, given the cross-sectional nature of the study, causal conclusions cannot be drawn.

Despite these shortcomings, eating behavior style, especially external eating, should be considered when designing proper interventions for EDs characterized by binge eating, i.e., $\mathrm{BN}$ and BED. Given that external eaters are more sensible to obesogenic environment, CET may help them to reduce reactivity to food-related cues and, hence, the probability of bingeing. Once proved that VR-based exposure is a suitable method to induce food-craving in external eaters with ED, VR-based CET could be proposed to enhance the efficacy of CBT in patients with high levels of external eating and to overcome logistical problems previously encountered with in vivo CET. Although some studies have reported difficulties with virtual food inducing psychophysiological responses in participants (Ledoux et al., 2013), most of research supports its suitability (Agliaro-López et al., 2014; Ferrer-Garcia et al., 2013; Ferrer-Garcia, GutiérrezMaldonado, Treasure et al., 2015). Indeed, Boswell and Kober (2016) recently showed that reactivity to visual food cues (e.g., pictures and videos) was as strongly predictive of eating behavior as reactivity to real food cues, and that visual cues were more strongly predictive than olfactory cues. Future research should test whether VR-based CET is especially effective in patients with an external eating style.

\section{Acknowledgments}

This study was supported by the Spanish Ministry of Science and Innovation, Project PSI2011- 
28801 (MINECO/FEDER/UE): "Tratamiento de la bulimia nerviosa mediante exposición a señales con realidad virtual" (Treatment of BN with virtual reality based cue-exposure therapy).

\section{References}

Agliaro-López, M., Ferrer-Garcia, M., Pla-Sanjuanelo, J., \& Gutiérrez-Maldonado, J. (2014). Inducción de craving por comida mediante realidad virtual no inmersiva [Inducing food craving by means of non-immersive virtual reality]. Revista de Psicopatología y Psicología Clínica, 19(3), 243-251. http://doi.org/10.5944/rppc.vol.19.num.3.2014.13905

Aimé, A., Cotton, K., \& Bouchard, S. (2009). Reactivity to virtual reality immersions in a subclinical sample of women concerned with their weight and shape. Journal of Cybertherapy and Rehabilitation, 2(2), 115-126.

American Psychiatric Association (2013). Diagnostic and statistical manual of mental disorders (5th ed.). Arlington, VA: American Psychiatric Publishing.

Blundell, J. E., Stubbs, R. J., Golding, C., Croden, F., Alam, R., Whybrow, S., ... Lawton, C. L. (2005). Resistance and susceptibility to weight gain: Individual variability in response to a high-fat diet. Physiology and Behavior, 86(5), 614-622. http://doi.org/10.1016/j.physbeh.2005.08.052

Boswell, R. G., \& Kober, H. (2016). Food cue reactivity and craving predict eating and weight gain: A meta-analytic review. Obesity Reviews, 17(2), 159-177. http://doi.org/10.1111/obr.12354

Braet, C., \& Van Strien, T. (1997). Assessment of emotional, externally induced and restrained eating behaviour in nine to twelve-year-old obese and non-obese children. Behaviour Research and Therapy, 35(9), 863-873. http://doi.org/10.1016/S00057967(97)00045-4

Brendgen, M., Girard, A., Vitaro, F., Dionne, G., \& Boivin, M. (2015). Gene-Environment correlation linking agression and peer victimization: Do classroom behavioral norms matter? Journal of Abnormal Child Psychology, 43(1), 19-31. 
560 Brockmeyer, T., Hahn, C., Reetz, C., Schmidt, U., \& Friederich, H.C. (2015). Approach bias 561 and cue-reactivity towards food in people with high versus low levels of food craving. $562 \quad$ Appetite, 95, 197-202.

563

564

565

566

567

568

569

570

571

572

573

574

575

576

577

578

579

580

581

582

583

584

585

586

587

Bruch, H. (1964). Psychological aspects in overeating and obesity. Psychosomatics, 5, 269274.

Bulik, Sullivan, Carter, McIntosh, \& Joyce. (1998). The role of exposure with response prevention in the cognitive-behavioural therapy for bulimia nervosa. Psychological Medicine, 28(3), 611-623.

Burton, P., Smith, H.J., \& Lightowler, H.J. (2007). The influence of restrained and external eating patterns on overeating. Appetite, 49(1), 191-197.

http://doi.org/10.1016/j.appet.2007.01.007

Calle, E.E., Teras, L.R., \& Thun, M.J. (2005). Obesity and mortality. The New England Journal Medicine, 353, 2197-2199.

Capodaglio, P., Faintuch, J., \& Liuzzi, A. (Eds.). Disabling obesity. From determinants of disability to care models (pp. 269-284). New York, NY: Springer-Verlag Berlin Heidelberg.

Cebolla, A., Barrada, J. R., van Strien, T., Oliver, E., \& Baños, R. (2014). Validation of the Dutch Eating Behavior Questionnaire (DEBQ) in a sample of Spanish women. Appetite, 73, 58-64. http://doi.org/10.1016/j.appet.2013.10.014

Cepeda-Benito, A., Fernandez, M.C., Moreno, S. (2003). Relationship of gender and eating disorder symptoms to reported cravings for food: Construct validation of state and trait craving questionnaires in Spanish. Appetite, 40, 47-54.

Chao, A.M., Grilo, C.M., \& Sinha, R. (2016). Food cravings, binge eating, and eating disorder psychopathology: Exploring the moderating roles of gender and race. Eating Behaviors, 21, 41-47.

Cohen, J., Cohen, P., West, S. G., \& Aiken, L. S. (2003). Applied Multiple

Regression/Correlation Analysis for the Behavioral Sciences (3rd ed.). New Jersey: Laurence Erlbaum. 
588

589

590

591

592

593

594

595

596

597

598

599

600

601

602

603

604

605

606

607

608

609

610

611

612

613

614

615

616

Dakanalis, A., Carrà, G., Calogero, R., Fida, R., Clerici, M., Zanetti, M.A., \& Riva, G. (2015). The developmental effects of media-ideal internalization and self-objectification processes on adolescents' negative body-feelings, dietary restraint, and binge eating. European Child \& Adolescent Psychiatry, 24(8), 997-1010

Dakanalis, A., Timko, C. A., Carrà, G., Clerici, M., Zanetti, M. A., Riva, G., \& Caccialanza, R. (2014). Testing the original and the extended dual-pathway model of lack of control over eating in adolescent girls. A two-year longitudinal study. Appetite, 82, 180-193.

Dakanalis, A., Zanetti, M. A., Clerici, M., Madeddu, F., Riva, G., \& Caccialanza, R. (2013). Italian version of the Dutch Eating Behavior Questionnaire. Psychometric proprieties and measurement invariance across sex, BMI-status and age. Appetite, 71, 187-195. http://doi.org/10.1016/j.appet.2013.08.010

Davis, C., Levitan, R.D., Smith, M., Tweed, S., \& Curtis, C. (2006). Associations among overeating, overweight, and attention deficit/hyperactivity disorder: A structural equation modelling approach. Eating Behaviors, 7, 266-274.

Deaver, C.M., Miltenberger, R.G., Smyth, J., Meidinger, A., \& Crosby, R. (2003). An evaluation of affect and binge eating. Behavior Modification, 27, 578-599.

Delahanty, L.M., Meigs, J.B., Hayden, D., Williamson, D.A., \& Nathan, D.M. (2002). Psychological and behavioural correlates of baseline BMI in the diabetes prevention program (DPP). Diabetes care, 25, 1992-1998.

Elosua, P., \& López-Jáuregui, A. (2012). Internal structure of the Spanish adaptation of the Eating Disorder Inventory-3. European Journal of Psychological Assessment, 28(1), 2531.

Elosua, P., López-Jáuregui, A., \& Sánchez-Sánchez, F. (2010). Manual técnico con la adaptación al español del Eating Disorder Inventory-3. Madrid: TEA Ediciones.

Ferrer-Garcia, M., Gutiérrez-Maldonado, J., Pla-Sanjuanelo, J., Vilalta-Abella, F., AndreuGracia, A., Dakanalis, A., Fernandez-Aranda, F., Fusté-Escolano, A., Ribas-Sabaté, J., Riva, G., Saldaña, C., Sánchez, I. (2015). External eating as a predictor of Cue-reactivity to food-related virtual environments. Studies in Health Technology and Informatics, $13(219), 117-122$. 
617

618

619

620

621

622

623

624

625

626

627

628

629

630

631

632

633

634

635

636

637

638

639

640

641

642

643

644

Ferrer-Garcia, M., Gutiérrez-Maldonado, J., \& Riva, G. (2013). Virtual Reality Based Treatments in Eating Disorders and Obesity: A Review. Journal of Contemporary Psychotherapy, 43(4), 207-221. http://doi.org/10.1007/s10879-013-9240-1

Ferrer-Garcia, M., Gutiérrez-Maldonado, J., Caqueo-Urízar, A., \& Moreno, E. (2009). The validity of virtual environments for eliciting emotional responses in patients with eating disorders and in controls. Behavior Modification, 33, 830-854. http://doi.org/10.1177/0145445509348056

Ferrer-Garcia, M., Gutiérrez-Maldonado, J., Pla-Sanjuanelo, J., Vilalta-Abella, F., AndreuGracia, A., Dakanalis, A., ... Sánchez, I. (2015). External Eating as a Predictor of Cuereactivity to Food-related Virtual Environments. Studies in Health Technology and Informatics, 219, 117-22.

Ferrer-Garcia, M., Gutiérrez-Maldonado, J., Treasure, J., \& Vilalta-Abella, F. (2015). Craving for food in virtual reality scenarios in non-clinical sample: Analysis of its relationship with body mass index and eating disorder symptoms. European Eating Disorders Review, 23(5), 371-378.http://doi.org/10.1002/erv.2375

Ferriday, D., \& Brunstrom, J. M. (2011). “I just can”t help myself': effects of food-cue exposure in overweight and lean individuals. International Journal of Obesity, 35(1), 142149. http://doi.org/10.1038/ijo.2010.117

Garner, D. M. (2004). EDI 3: Eating disorder inventory-3: Professional manual. Psychological Assessment Resources.

Garner, D. M. (2008). Eating disorder inventory-3. Firenze: Organizzazioni Speciali.

Goossens, L., Braet, C., Van Vlierberghe, L., \& Mels, S. (2009). Loss of control over eating in overweight youngsters: The role of anxiety, depression and emotional eating. European Eating Disorders Review, 17, 68-78. DOI: 10.1002/erv.892

Gorini, A., Griez, E., Petrova, A., \& Riva, G. (2010). Assessment of the emotional responses produced by exposure to real food, virtual food and photographs of food in patients affected by eating disorders. Annals of General Psychiatry. http://doi.org/10.1186/1744$859 X-9-30$ 
645 Greeno, C.G., Wing, R.R., \& Shiffman, S. (2000). Binge antecedents in obese women with 646 and without binge eating disorder. Journal of Consulting and Clinical Psychology, 68(1), $647 \quad 95-102$.

648 Gutiérrez-Maldonado, J., Ferrer-Garcia, M., \& Riva, G. (2013). VR cue-exposure treatment 649 for bulimia nervosa. Annual Review of Cybertherapy and Telemedicine, 21-25. 650 http://doi.org/10.3233/978-1-61499-282-0-21

651 Gutiérrez-Maldonado, J., Ferrer-García, M., Caqueo-Urízar, A., \& Moreno, E. (2010). Body 652 image in eating disorders: The influence of exposure to virtual-reality environments. Cyberpsychology, Behavior and Social Networking, 13(5), 521-531. http://doi.org/10.1089/cyber.2009.0301

Gutiérrez-Maldonado, J., Wiederhold, B. K., \& Riva, G. (2016). Future Directions: How 656 Virtual Reality Can Further Improve the Assessment and Treatment of Eating Disorders and Obesity. Cyberpsychology, Behavior, and Social Networking, 19(2), 148-53. http://doi.org/10.1089/cyber.2015.0412

Herman, C. P., \& Polivy, J. (2008). External cues in the control of food intake in humans: http://doi.org/10.1016/j.physbeh.2008.04.014

Herman, P., \& Polivy, J. (2005). Normative influences of food intake. Physiology \& 663 Behavior, 86, 762-772.

Hetherington, M.M., \& Mcdiarmid, J.I. (1995). Pleasure and excess: Liking for and overconsumption of chocolate. Psysiology \& Behavior, 57(1), 27-35.

Hill, A., Weaver, C.F.L., \& Blundell, J.E. (1991). Food craving, dietary restraint and mood. 667 Appetite, 17, 187-197.

Jansen, A. (1998). A learning model of binge eating: Cue reactivity and cue exposure. Behaviour, Research and Therapy, 36(3), 257-272. addictive-like eating and problematic eating outcomes. Eating Behaviors, 19, 98-101. 
672 Koskina, A., Campbell, I. C., \& Schmidt, U. (2013). Exposure therapy in eating disorders 673 revisited. Neuroscience and Biobehavioral Reviews, 37(2), 193-208.

674 http://doi.org/10.1016/j.neubiorev.2012.11.010

675 Ledoux, T., Nguyen, A.S., Bakos-Block, C., \& Bordnick, P. (2013). Using virtual reality to 676 study food cravings. Appetite, 71, 396-402.

677 Leehr, E. J., Krohmer, K., Schag, K., Dresler, T., Zipfel, S., \& Giel, K.E. (2015). Emotion 678 regulation model in binge eating disorder and obesity: a systematic review. Neuroscience 679 \& Biobehavioral Reviews, 49, 125-134.

680

Maffeis, C. (2000). Aetiology of overweight and obesity in children and adolescents. European Journal of Pediatrics, 159, 35-44.

Malnick, S. D. H., \& Knobler, H. (2006). The medical complications of obesity. QJM: An International Journal of Medicine, 99(9), 565-579.

Martínez-Mallén, E., Castro-Fornieles, J., Lázaro, L., Moreno, E., Morer, A., Font, E., ... Toro, J. (2007). Cue exposure in the treatment of resistant adolescent bulimia nervosa. International Journal of Eating Disorders, 40(7), 596-601. http://doi.org/10.1002/eat.20423

Mason, T. B., \& Lewis, R. J. (2014). Profiles of Binge Eating: The Interaction of Depressive Symptoms, Eating Styles, and Body Mass Index. Eating Disorders, 22(5), 450-460. http://doi.org/10.1080/10640266.2014.931766

Mensorio, M.S., Cebolla, A., Lisón, J.F., Rodilla, E., Palomar, G., Miragall, M., \& Baños, R.M. (2016). Emotional eating as a mediator between anxiety and cholesterol in population with overweight and hypertension. Psychology, Health, \& Medicine, 1-8. http://dx.doi.org/10.1080/13548506.2016.1271134

Nammi, S., Saisudha, K., Chinnala, k.M., \& Boini, K.M. (2004). Obesity: An overview on its current perspectives and treatment options. Nutrition Journal, 3, 3.

Nederkoorn, C., \& Jansen, A. (2002). Cue reactivity and regulation of food intake. Eating Behaviors, 3(1), 61-72. http://doi.org/S1471015301000459 [pii] 
699

700

701

702

703

704

705

706

707

708

709

710

711

712

713

714

715

716

717

718

719

720

721

722

723

724

725

726

Nederkoorn, C., Smulders F.T., Havermans, R., \& Jansen, A. (2004). Exposure to binge food in bulimia nervosa: Finger pulse amplitude as a potential measure of urge to eat and predictor of food intake. Appetite, 42(2), 125-130.

Nederkoorn, C., Smulders, F. T., \& Jansen, A. (2000). Cephalic phase responses, craving and food intake in normal subjects. Appetite, 35(1), 45-55.

http://doi.org/10.1006/appe.2000.0328

Neel, J.V. (1962). Diabetes mellitus: a "thrifty" genotype rendered detrimental by "progress"? American journal of human genetics, 14(4), 353-362.

Neumark-Sztainer, D., Sherwood, N.E., French, S.A., Jeffery, R.W. (1999). Weight control behaviors among adult men and women: cause or concern? Obesity Research, 7(2), 179188.

Parker, B.A., Sturm, K., MacIntosh, C.G., Feinle, C., Horowitz, M., \& Chapman, I.M. (2004). Relation between food intake and visual analogue scale ratings of appetite and other sensations in healthy older and young subjects. European Journal of Clinical Nutrition, 58(2), 212-218.

Pelchat, M.L. (1997). Food cravings in young and elderly adults. Appetite, 28(2), 103113.

Pla-Sanjuanelo, J., Ferrer-García, M., Gutiérrez-Maldonado, J., Riva, G., Andreu-Gracia, A., Dakanalis, A., ... Sanchez-Planell, L. (2015). Identifying specific cues and contexts related to bingeing behavior for the development of effective virtual environments. Appetite, 87, 81-9. http://doi.org/10.1016/j.appet.2014.12.098

Pla-Sanjuanelo, J., Ferrer-Garcia, M., Vilalta-Abella, F., Riva, G., Dakanalis, A., RibasSabaté, J., ... Gutiérrez-Maldonado, J. (submitted) Effectiveness of a new Virtual Reality Cue-Exposure System for evoking Food Craving and Anxiety in Bulimia Nervosa and Binge Eating Disorder.

Riva, G., Gaggioli, A., \& Dakanalis, A. (2013). From body dissatisfaction to obesity. How virtual reality may improve obesity prevention and treatment in adolescents. Studies in Health Technology and Informatics, 184, 356-362. 
727

728

729

730

731

732

733

734

735

736

737

738

739

740

741

742

743

744

745

746

747

748

749

750

751

752

753

754

755

Rodin (1981). Current status of the internal-external hypothesis for obesity. American Psychologist, 36, 361-372.

Satta, V., Scherma, M., Giunti, E., Collu, R., Fattore, L., Fratta, W., \& Fadda, P. (2016). Emotional profile of female rats showing binge eating behavior. Physiology \& Behavior, $163,136-142$.

Schachter, S. (1971). Some extraordinary facts about obese humans and rats. The American Psychologist, 26(2), 129-144. http://doi.org/10.1037/h0030817

Schulte, E. M., Grilo, C.M., Gearhardt, A.N. (2016). Shared and unique mechanisms underlying binge eating disorder and addictive disorders. Clinical Psychology Review, 44, 125-139.

Sonneville, K. R., Horton, N. J., Micali, N., Crosby, R. D., Swanson, S. A., Solmi, F., \& Field, A.E. (2013). Longitudinal associations between binge eating and overeating and adverse outcomes among adolescents and young adults. Does loss of control matter? JAMA Pediatrics, 167(2), 149-155.

Stevens, J. (1996). Applied multivariate statistics for the social sciences ( $3^{\text {rd }}$ edition). New Jersey: Lawrence Erlbaum.

Tanofsky-Kraff, M., Yanovski, S. Z., Schvey, N. A., Olsen, C. H., Gustafson, J., \& Yanovski, J. A. (2009). A prospective study of loss of control eating for body weight gain in children at high risk for adult obesity. The International Journal of Eating Disorders, 42(1), 26-30.

Tetley, A., Brunstrom, J., \& Griffiths, P. (2009). Individual differences in food-cue reactivity. The role of BMI and everyday portion-size selections. Appetite, 52(3), 614-620.

Van Strien, T., \& Ouwens, M. A. (2007). Effects of distress, alexithymia and impulsivity on eating. Eating Behaviors, 8, 251-257.

Van Strien, T., \& Ouwens, M.A. (2003). Counterregulation in female obese emotional eaters: Schachter, Goldman, and Gordon's (1968) test of psychosomatic theory revisited. Eating Behaviors, 3, 329-340.

Van Strien, T., Frijter, J.E.R., Bergers, G.P.A., \& Defares, P.B. (1986). The Dutch Eating Behavior Questionnaire (DEBQ) for assessment of restrained, emotional, and external eating behavior. International Journal of Eating Disorders, 5, 295-315. 
van Strien, T., Herman, C. P., \& Verheijden, M. W. (2009). Eating style, overeating, and overweight in a representative Dutch sample. Does external eating play a role? Appetite, 52(2), 380-387. http://doi.org/10.1016/j.appet.2008.11.010

van Strien, T., Herman, C.P., \& Anschutz, D. (2012). The predictive validity of the DEBQexternal eating scale for eating in response to food commercials while watching television. International Journal of Eating Disorders, 45(2), 257-62. http://doi.org/10.1002/eat.20940

van Strien, T., Herman, C.P., \& Verheijden, M. W. (2012). Eating style, overeating and weight gain. A prospective 2-year follow-up study in a representative Dutch sample. Appetite, 59(3), 782-789. http://doi.org/10.1016/j.appet.2012.08.009

Waller, G. \& Matoba, M. (1999). Emotional eating and eating psychopathology in nonclinical groups: A cross-cultural comparison of women in Japan and the United Kingdom. International Journal of Eating Disorders, 26, 333-340.

Wardle, J., Marsland, L., Sheikh, Y., Quinn, M., Fedoroff, I., \& Ogden, J. (1992). Eating style and eating behavior in adolescents. Appetite, 18, 167-183.

Waters, A., Hill, A., \& Waller, G. (2001). Bulimics' responses to food cravings: is bingeeating a product of hunger or emotional state? Behaviour Research and Therapy, 39(8), 877-886.

Weingarten, H.P., \& Elston, D. (1991) Food Cravings in a College Population. Appetite, 17, 167-175.

World Health Organization (2015). Noncommunicable disease progress monitor. Geneva: World Health Organization. 